\title{
PRELIMINARY REPORT ON FOSSIL VERTEBRATES OF THE SAN PEDRO VALLEY, ARIZONA, WITH DESCRIPTIONS OF NEW SPECIES OF RODENTIA AND LAGOMORPHA.
}

\author{
By James W. Gidley.
}

INTRODUCTION.

On the initiative of the United States Geological Survey and with the cooperation of the United States National Museum, I was privileged during February, March, and part of April, 1921, to collect fossil vertebrates in the San Pedro Valley, Ariz., where remains had previously been located by Kirk Bryan, of the Geological Survey. The results of this expedition are here published in part.

The special problem involved was the determination of the age of the sedimentary deposits, which up to that time had been termed Pleistocene. Two localities, apparently at slightly different horizons, yielded material representing a fauna sufficiently varied and distinctive to establish their age as Pliocene.

The locality first visited is a small area of badlands about 3 miles east of the Curtis ranch, which is on the State road about 14 miles northwest of Tombstone and an equal distance southeast of Benson by road. The second locality is west of the State road about 2 miles south of Benson. These two localities are about 12 miles apart and on opposite sides of the San Pedro Valley. The first locality yielded by far the greater bulk of material, but the species represented in the collection from the second are more numerous. Stratigraphically there seems to be no difference in the level of the beds of the two localities, and structurally they are very similar, yet, so far as I am able to determine, they contain no species in common. Because of this fact, as well as the general character and assemblage of the forms represented, I am led to consider them as of slightly different age, the beds at the Benson locality being apparently the older.

Most of the mammal material is fragmentary, but several good specimens were procured, including enough material for the restoration of the dermal armor and skeleton of a Glyptotherium and a possible skeletal restoration of a mastodon, both from the Curtis locality. The material from the Benson locality here described was all collected at one spot, a fossil bone quarry opened up and worked by Kirk Bryan and me. Immediately associated material from this quarry includes fragmentary specimens of Hipparion, Pliauchena?, Platygonus, and Pliohippus or Hippidium?, together with a new species of box turtle and eight new species of birds, not all of which are satisfactorily definable from the scanty material obtained.

The greater part of the specimens included in these collections have not yet been prepared, but those belonging to the orders Rodentia and Lagomorpha have been cleaned and studied, and the new species are here described. Those from the Curtis locality were all found during the excavation of one of the mastodon skeletons. Immediately associated with them were remains of a llama, a canid, a mustilid, a small land turtle, an edentate, and two species of small birds.

A tentative list of the orders, families, genera, and species, so far as they have been determined, represented in each locality is given on page 120 . 
Preliminary list of fossil vertebrates from the San Pedro Valley, Ariz.

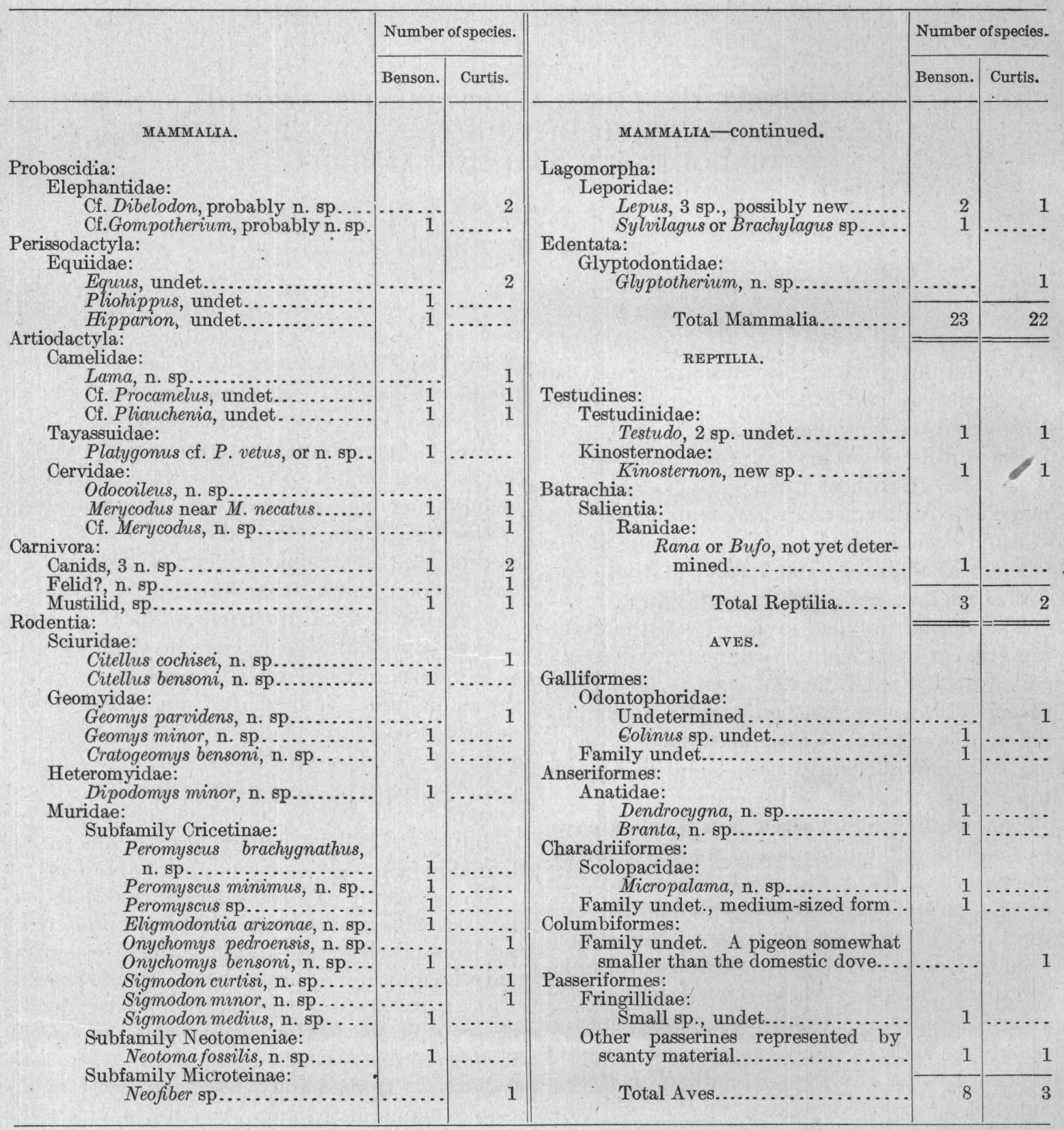

The reptilian remains, including at least two species of turtles, probably new, are being described by C. W. Gilmore, and the bird bones are being studied and will be described by Alexander Wetmore, of the Biological Survey, Department of Agriculture. The tentative lists of Reptilia and Aves given above are furnished by these gentlemen.

\section{GEOLOGIC HORIZON AND CLIMATIC CONDITIONS INDICATED.}

This preliminary study reveals littie positive evidence regarding the exact geologic horizon of the beds in San Pedro Valley, beyond what is stated above. They seem to be clearly Pliocene, and the peculiar mingling of modern and more ancient forms seems to point rather 
definitely to a late stage of Pliocene time. Unfortunately, the material of these collections represents for the most part new species that can not be correlated with known faunas of other localities where the age of the beds has been established. However, the species are sufficiently numerous and varied to constitute a standard for eomparison,' and future field work in this region will almost certainly bring to light material that wili definitely and correctly determine the proper sequence of these deposits.

The facts that there are here two or three species of true horse (Equus) and that the rodents are all referable to modern genera, some of which are found living in this general region, may suggest Pleistocene age. But to offset this evidence of a seemingly more modern fauna, the mastodons and glyptodonts are of distinctly Pliocene types, and one of the canids, though modern in skull and dental modifications, has the type of humerus belonging to the Miocene and Pliocene canids, in that the entepicondylar foramen is prominently present. This feature and the presence of Hipparion, Pliohippus, and Merycodus, together with the fact that the 15 or more species of rodents include no living species, constitute rather conclusive evidence of a faunal assemblage that is older than Pleistocene.

This general assemblage of species, including proboscidians, camels, horses, glyptodonts, and an extinct species of the ocellated turkey related to a group now living only in Central America and southern Mexico, suggests that the climate at the time the beds were laid down was rather warm and moist, probably subtropical or even tropical.

The presence of a true llama, the glyptodont, and a rodent belonging to a genus now living only in South America seems to indicate an intermingling of forms of South American origin, and the presence in these Pliocene deposits of a rodent and camel of definite South American living types suggests the derivation of their South American relatives from North America and favors the suggestion of an exchange of faunas between the two continents which took place somewhere near this epoch of geologic time.

\section{DESCRIPTIONS OF SPECIES.}

\section{Order RODENTIA.}

The order Rodentia is represented in the San Pedro Valley by 17 species, 11 of which occur at the Benson locality and 6 at the Curtis locality. Of these species, 15 are here described as new, and 2 are not certainly determined on the scanty material in hand. However, though all the species represented seem to be new, each is readily referable to one of ten living genera, distributed among four families - the Sciuridae, Geomyidae, Heteromyidae, and Muridae. The species belonging to the Muridae represent three. subfamilies - the Cricetinae, Neotomeniae, and Microteinae.

\section{Family SCIURIDAE.}

The family Sciuridae is represented by two new species, both belonging to the genus Citellus.

\section{Citellus cochisei Gidley, n. sp.}

Plate XXXIV, figures 1, 2.

Type.-Portion of a right maxillary containing all the cheek teeth (catalog No. 10490, U. S. Nat. Mus.).

Paratype.-Portion of a left lower jaw (cata$\log$ No. 10491).

Locality.-Both are from the Curtis locality, in sec. 25, T. 18 S., R. 21 E., and were found in exhuming a mastodon skeleton.

Description.-Length of upper cheek-tooth series 10.5 millimeters. Molars relatively wide, $\mathrm{m}^{1}$ and $\mathrm{m}^{2}$ one-third wider than long; lophs and valleys simple and narrow; both posterior transverse lophs of the molars completely united with protocone, forming a short, narrow valley opening outward and extending inward not more than one-half the width of the tooth crown, as in Cynomys. The anterior transverse lophs are more depressed and except in $\mathrm{m}^{3}$ are much longer than the other lophs, extending inward and upward to disppear in the anterior wall of the protocone. $\mathrm{P}^{4}$ differs from the anterior two molars only in being less wide and in having the anterior loph relatively and actually more extended anteriorly.

In the greater width of tooth crowns, the less extent of their median external reentrant valleys, and the relative shortness of the heel of the last molar, this species suggests Cynomys, 
but it differs from species of that genus in the much more brachyodont tooth crowns, the greater relative depth of the median external reentrant valleys, and the incipiency, amounting to almost total absence, of the posterior reentrant valleys so prominent in species of Cynomys. The first of these features might be considered as a character of degree only, indicating less advanced specialization, but the other two I consider characters that denote relationship with the living species of Citellus rather than with those of the genus Cynomys.

The lower jaw, as indicated by specimen No. 10491, which carries the incisor and the anterior two cheek teeth, is relatively short and deep, the incisor narrow and pointed, and the cheek teeth relatively wide to a degree corresponding with those of the upper series. This species compares in size with C. evermani, but it differs from all the living forms in one or more of the characters enumerated above.

Citellus bensoni Gidley, n. sp.

Plate XXXIV, figures 3, 4.

Type.-A first or second upper molar of the right side and a last upper molar of the left side (catalog No. 10531, U. S. Nat. Mus.).

Paratype.-The cheek-tooth series of a left lower jaw (catalog No. 10532, U. S. Nat. Mus.).

Locality.-Both from the Benson locality.

Description:-Length of cheek-tooth series (estimated from measurements of the paratype), 10.3 millimeters; upper molar of about the same proportion as the corresponding one of $C$. cochisei at the base but much narrower at the summit, owing to the greater slope of the inner wall of the protocone; the three transverse lophs about equal in length, the posterior one being broken up into two distinct but slightly joined cuspules, the inner one of which is a rounded cone entirely disconnected from the protocone.

An upper $\mathrm{m}^{3}$ which I associate with the type specimen, like that of $C$. cochisei, has a relatively small heel portion as compared with living species, and in addition there is a welldefined isolated cone-shaped cuspule near the center of the posterior basin.

This species seems to approach $C$. beecheyi much more closely than any other living species but differs from it in a few apparently important particulars. In $C$. beecheyi the crowns of the upper molars are relatively narrower than in the fossil species, being nearly as long as wide; the lingual wall of the protocone is less sloping, and the exterior or buccal face of this cusp is much more sloping. Other differences noted in the living species are the generally less broken up condition of the posterior transverse lophs; the somewhat shallower transverse valleys, the posterior one of which usually has a small cuspule at its external entrance; and the relatively broader and less completely inclosed posterior valley of the last upper molar.

Beyond the fact that the last lower molar, like the upper, is relatively smaller, and the valleys and cusps are somewhat more sharply defined than in $C$. beecheyi, there is little to distinguish between the lower cheek teeth of that species and $C$. bensoni.

\section{Family GEOMYIDAE.}

Three new species referable to two living genera of geomids are represented in the collection.

\section{Geomys parvidens Gidley, n. sp.}

Plate XXXIV, figures 5, 6 .

Type.-The anterior portion of a skull carrying the incisors and all the cheek teeth except the first and last of the right side (catalog No. 10492, U. S. Nat. Mus.).

Paratype.-Portion of the right lower jaw carrying all the teeth except $\mathrm{m}^{3}$ (catalog No. 10493, U. S. Nat. Mus.).

Locality.-Both from the Curtis locality.

Description.-Length of upper cheek-tooth series 5.5 millimeters; width across first upper molars (measured to outer borders) 6.7 millimeters; size small, about the same as that of Geomys texensis; rostrum relatively short and heavy; incisors with two very unequal grooves, the smaller one close to the inner border of the crown, the larger one almost exactly bisecting its anterior face, making the outer of the three ridges thus formed slightly but definitely largest; the cheek teeth are relatively small and not greatly expanded laterally, $\mathrm{m}^{1}$ and $\mathrm{m}^{2}$ being almost evenly elliptical in outline but with the outer edges slightly compressed; $\mathrm{p}^{4}$ with anterior lobe decidedly smaller and less laterally expanded than the posterior one; $\mathrm{m}^{3}$ as wide as long, subtriangular, relatively small.

Besides being about equal in size to $G$. texensis, G. parvidens is almost identical with that 
species in the character of the incisors, but it differs from $G$. texensis and the other living species of the genus in general in the less lateral expansion of the cheek teeth, the shorter and deeper rostrum, and the less progressive character of $\mathrm{p}^{4}$.

The lower jaw referred to this species is relatively short, with prominent masseteric ridge and the submental foramina lying almost directly under the anterior end of the masseteric ridge. The anterior lobe of $p_{4}$ is relatively small and subcircular, with the walls very little flattened.

Geomys minor Gidley, n. sp.

Plate XXXIV, figures 7,8 .

Type.-Portion of a right lower jaw lacking the last molar (catalog No. 10494, U. S. Nat. Mus.).

Paratype.-A right upper incisor (catalog No. 10534, U. S. Nat. Mus.).

Locality.-Both from the Benson locality.

Description.-Length of cheek-tooth series (estimated) 5.4 millimeters; the jaw is slightly smaller than that of $G$. parvidens and differs from it otherwise in having the anterior masseteric area more depressed, the submental foramen slightly farther back in position, the cheek teeth relatively larger, and the anterior lobe of $\mathrm{p}_{4}$ more nearly circular in outline; no anterior fossa between cheek teeth and coronoid process.

An associated upper incisor tooth is of appropriate size for the species It shows the characteristic grooving of a true Geomys, and it is this fact which has determined the generic reference of $G$. minor.

\section{Cratogeomys bensoni Gidley, n. sp.}

Plate XXXIV, figures 9-11.

Type.-A portion of a left lower jaw carrying all teeth (incisors broken) (catalog No. 10495, U. S. Nat. Mus.).

Paratype.-An upper incisor (catalog No. 10496, U. S. Nat. Mus.).

Locality.-Benson locality. The species is represented by four other pieces of the lower jaws from the same locality.

Description.-Length of cheek-tooth series 8 millimeters (measured at summits of teeth). About the size of the living species Geomys breviceps; cheek teeth not greatly compressed; $\mathrm{p}^{4}$ with outer reentrant angle rather widely $V$-shaped, the inner one forming a distinct $U$; posterior wall of last molar in the type specimen with two distinct and two faint parallel longitudinal grooves forming three low but distinct closely grouped median longitudinal enamel ridges.

This species differs from all living species of geomids examined in having the area of the anterior portion of the masseteric ridge more depressed and in the position of the anterior submental foramen, which is nearly as in the two above-described species of Geomys. In living species this foramen is anterior to the masseteric ridge and nearly level with it. In the fossil species it is lower and more posterior in position, lying almost directly under the anterior extremity of the masseteric ridge. There is also between the cheek teeth and the anterior border of the coronoid process in $C$. bensoni a narrow but distinctly marked longitudinal fossa.

This species is referred to Cratogeomys on the evidence of an associated upper incisor of appropriate size which has the single groove characteristic of this genus.

\section{Dipodomys minor Gidley, n. sp.}

Plate XXXIV, figure 16

Type.-A nearly complete right lower jaw containing the incisor and the first cheek tooth (catalog No. 10499, U. S. Nat. Mus.).

Locality.-Benson locality.

Description.-Length of cheek-tooth row, measured from extreme borders of the alveoli, 4.7 millimeters; size and general jaw characters about as in the living species Perodipus chapmani, differing only in its more slender proportions and in the somewhat more reduced condition of the coronoid process. The fourth lower premolar, the only one of the cheek-teeth series present, is a long crowned and anteriorly curved tooth which is double-lobed, the anterior lobe having an anterior reentrant angle as in $P$. chapmani, but this tooth differs from the tooth of that species in having the posterior lobe relatively wider. Also the alveolus of the last molar is only about one-half the width of that of the other molars, indicating that this tooth is relatively more reduced than in the living species. 


\section{Family MURIDAE.}

The family Muridae is rather abundantly represented at both localities. The 12 determinable species are distributed among three subfamilies, 10 belonging to the Cricetinae, 1 to the Microtinae, and 1 to the Neotomeniae.

Genus PEROMYsCUS.

Specimens found at the Benson locality are referable to three species of Peromyscus. Two of these are new, although one is apparently closely related to the $P$. taylori group. The other new species is more distinctive. The third, represented by a single lower jaw lacking the cheek teeth, has not been determined.

Peromyscus brachygnathus Gidley, n. sp.

Plate XXXIV, figure 12.

Type.-The greater portion of a right lower jaw carrying all the teeth (catalog No. 10501, U. S. Nat. Mus.).

Locality. - Curtis locality.

Description.-Length of cheek-tooth series, 2.8 millimeters; about the size of $P$. taylori; jaw relatively short anterior to cheek teeth; last molar very much reduced, as much as in any living species of Onychomys. The teeth are too much worn to determine accurately their normal height in unworn condition, but they appear to be of the depressed type of $P$. taylori.

The form and position of the anterior extension of the masseteric ridge, the general character of the coronoid region, and the relatively broadly expanded anterior lobe of the anterior cheek tooth seem to determine the generic reference of this species, but it differs from all living species of the genus in the relatively short jaw and the greater reduction of the last lower cheek tooth, which seems to have nearly or quite lost its hinder lobe.

\section{Peromyscus minimus Gidley, n. sp.}

Plate XXXIV, figure 13.

Type.-Portion of a left lower jaw carrying all the teeth (catalog No. 10500, U. S. Nat. Mus.).

Locality.-Benson locality.

Description.--Size very small, length of cheektooth series 2.6 millimeters; cheek-tooth cusps depressed, with well-marked cingula at the entrance of the external valley, and with tendency to inclose the internal ones by an up- rising of the inner enamel wall between the cusps; anterior lobe of the first cheek tooth, $\mathrm{p}_{4}$, relatively narrow but two-cusped at the summit; posterior lobe of last cheek tooth small, almost as much reduced as in Onychomys.

This species seems more nearly related to $P$. taylori than to any other living species but differs from it in having a narrow divided anterior lobe of the first cheek tooth and a more reduced hinder molar. It further differs from that species and more nearly agrees with others of the genus in the wider angle at which the coronoid portion of the ascending ramus diverges from the alveolar portion of the jaw.

$P$. minimus is distinguished from $P$. brachygnathus in that the jaw is somewhat more slender in proportions; the masseteric ridge is less advanced forward; the cheek teeth are slightly narrower; the anterior lobe of the first cheek tooth is narrow and double cusped, while that of $P$. brachygnathus is wider and undivided, and the last cheek tooth is somewhat less reduced.

\section{Peromyscus sp.}

Plate XXXIV, figure 14.

A second and larger species, about equaling Peromyscus m. gambeli in size, is represented by a lower jaw (catalog No. 10502, U.S. Nat. Mus.) lacking all the cheek teeth. Length of cheektooth series as estimated by measurement of the alveoli, 3.8 millimeters. This jaw, in its general form and in the position of the anterior extremity of the masseteric ridge, is sufficiently characterized to make certain its generic reference, but its specific features can not be determined until the cheek teeth are known.

\section{Genus ELIGMODONTIA.}

The genus Eligmodontia, the living species of which are confined to the South America continent, is represented by a single species in the fossil collection from Arizona.

Eligmodontia arizonae Gidley, n. sp.

Plate XXXIV, figure 15.

Type.-Greater portion of a left lower jaw containing the complete dentition (catalog No. 10503 , U. S. Nat. Mus.).

Paratype. - Single lower jaws of two other individuals (catalog Nos. 10504, 10505).

Locality.-All from Benson locality. 
Description.-Length of cheek-tooth series 3.6 millimeters; about the size of the living species $E$. morgani, but may be distinguished from it by its relatively greater depth of jaws, its decidedly shorter symphysis, and the less reduced condition of the last molar.

The anterior lobe of the first cheek tooth is distinctly notched by an anterior median reentrant angle, as is usual in Peromyscus, whereas in the living species of Eligmodontia this lobe is usually evenly convex in front. The fossil species from Arizona, however, is readily distinguished from Peromyscus by the characters which ally it to Eligmodontia, namely, by the form and position of the masseteric ridge, which extends forward to the extreme anterior border of the cheek-tooth series; by the form and situation of the capsular process for the reception of the base of the incisor, which is placed high upon the ascending ramus and is marked by a decided sulcus between it and the coronoid; and by the form of the last cheek tooth, which in species of Eligmodontia is more reduced than in Peromyscus.

Onychomys pedroensis Gidley, n. sp.

Plate XXXV, figure 1.

Type.-Portion of a left lower jaw carrying the first and last cheek teeth (catalog No. 10506, U. S. Nat. Mus.).

Paratypes.-Other lower jaw portions (catalog Nos. 10507, 10508, U. S. Nat. Mus.).

Locality.-All from Curtis locality.

Description.-Length of the cheek teeth 4.5 millimeters; size somewhat larger than O. leu. ruidosae, which it somewhat more nearly resembles than any other living species. It further differs from that species in its relatively greater depth of jaw, the greater degree to which the masseteric ridge is carried forward, and the somewhat less reduced condition of the last cheek tooth.

Onychomys bensoni Gidley, n. sp.

Plate XXXV, figure 3.

Type.-Portion of a right lower jaw containing complete dentition (catalog No. 10509, U. S. Nat. Mus.).

Locality.-Benson locality.

Description.-Length of cheek-tooth series 3.9 millimeters; about the size of $O$. torridus but with less reduced last molar, as in the larger species 0 . leu. ruidosae. The hinder lobe $91048^{\circ}-23-9$ of the last molar is less reduced even than in the last-mentioned species. O. bensoni differs from all the living species of the genus in having more widely open valleys and less conspicuous lophs in the molar teeth; a more depressed heel on the last lower molar, which is distinctly lower than the anterior or triconid portion; and apparently a relatively larger and higher coronoid process.

Sigmodon curtisi Gidley, n. sp.

Plate XXXV, figure 2.

Type.-The greater parts of both lower jaws carrying complete dentition (catalog No. 10510, U. S. Nat. Mus.).

Paratype.-Portion of a right lower jaw with cheek teeth (catalog No. 10511, U. S. Nat. Mus.).

Locality.-Both from Curtis locality.

Description.-Length of cheek-tooth series 7 millimeters; about the size of S. hispidus arizonae, which it seems to resemble more nearly, but it differs from that as well as the other living species in the more open valleys of the reentrant angles, the more compressed lophs, the less hypsodont condition of the cheek teeth, the relatively deeper posterior inner reentrant valley of $p_{4}$ and $m_{1}$, and especially the form and proportions of the cusps of the last lower molar, which is relatively larger, with the hinder cusp relatively broader and fuller than in the living species. A feature that is characteristic of this and the species described below and is not observed in any of the living species is noted in the last molar, in which the great extension and flattening of the inner or lingual wall of the posterior lobe forms a sharp right angle with the posterior wall of the reentrant angle on that side.

I take pleasure in naming this species for Mr. Milton Curtis, in recognition of his efficient assistance in the field.

\section{Sigmodon minor Gidley, n. sp. \\ Plate XXXV, figures 4,5 .}

Type.-Portion of a left lower jaw carrying the complete dentition (catalog No. 10512, U. S. Nat. Mus.).

Paratype.-Portion of a left maxillary carrying the anterior two cheek teeth (catalog No. 10513, U. S. Nat. Mus.).

Locality.-Curtis locality. Five other lowerjaw portions, most of them with complete 
dentition (catalog Nos. 10514 to 10518), are also referable to this species.

Description.-Length of cheek-tooth series 4.7 millimeters; smaller than S. medius and decidedly smaller than any of the living species examined. This species is distinguished from the living forms by the same characters observed in S. medius, except that the external reentrant valleys of the upper molars (as shown by specimen No. 10513) are of the normal modern type. S. minor differs from $S$. medius only in its smaller size, having a relatively narrower anterior lower cheek tooth, in which the anterior lobe is relatively smaller, with the adjacent reentrant valleys nearly equal in length. The reentrant valleys of the upper cheek teeth are oblique to the same degree and of about the same proportionate depth, but the molar crowns of both the upper and lower series are less hypsodont.

\section{Sigmodon medius Gidley, n. sp.}

Plate XXXV, figures 6, 7 .

Type.-Portion of a right lower jaw containing the complete dentition and an associated fragment of a right maxillary carrying the anterior two cheek teeth, possibly of the same individual (catalog No. 10519, U. S. Nat. Mus.).

Paratypes.-Four other lower-jaw portions (catalog Nos. 10520 to 10523 , U. S. Nat. Mus.).

Locality.-All from the Benson locality.

Description.- - Length of cheek-tooth series 5.5 millimeters; somewhat smaller than the living species $S$. sanctae martae, with which it seems to compare more nearly than with other living forms. Its resemblances are noted in the form of the anterior lobe of the first cheek tooth, in which the anterior internal reentrant valley considerably exceeds the opposing outer one in length; in the decided angulation of the posterior portion of the inner wall of the last molar; and in the relatively heavy symphysis and considerable depth of jaw. It differs from this and other living species in having the cheek-tooth crowns slightly less hypsodont, the reentrant valleys more open, and the lophs correspondingly narrower, while there is present in the last molar a small but distinct reentrant notch on its inner side opposite the posterior reentrant valley.

The two upper cheek teeth show the same character of the more open valleys observed in the lower cheek teeth. Another difference noted is the form of the external reentrant valleys of these teeth, which clearly distinguishes them from the corresponding teeth of living species. The external reentrant valleys, instead of being straight, open directly outward, while their inner portions bend backward, forming a decided angle in their posterior enamel walls. In the living species these valleys run obliquely forward and outward in a nearly straight or but slightly curved line.

Two other lower jaws in the collection (Nos. 10521 and 10522) differ slightly in minor characters from the type but are here referred to this species. These differences, which consist wholly in a somewhat smaller size and a less proportionate depth of jaw, correspond to differences observed between males an females of the living species. S. sanctae martae. I therefore assume that the type specimen and specimen No. 10520, which agrees with it in every particular, represent males, while the smaller jaws just mentioned represent females of the species.

\section{Neotoma fossilis Gidley, n. sp.}

Plate XXXV, figures 8-10.

Type.-Portion of a right maxillary carrying the anterior cheek tooth and the alveoli for middle cheek tooth (catalog No. 10524, U. S. Nat. Mus.).

Paratypes.-Portion of a left lower jaw carrying the incisor and alveoli for the cheek teeth, and two right lower cheek teeth (catalog Nos. 10525 and 10526 , U. S. Nat. Mus.).

Locality.-Benson locality.

Description.-Length of anterior cheek tooth 3.2 millimeters; width 2.2 millimeters; about the size of $N$. intermedia gilva. The following characters distinguished this from all living species: First upper cheek tooth relatively short and wide; no indication of an anterior internal reentrant valley; posterior internal reentrant valley nearly as long as the the external one; posterior notch of anterior palatial opening opposite the anterior root of the first cheek tooth.

The two lower teeth referred to this species also show distinctive characters. The anterior one $\left(p_{4}\right)$ is entirely devoid of the anterior reentrant valley so prominent in such a form as $N$. cinera, and both these teeth are like the corresponding ones of this species in having the 
posterior external reentrant valleys pitted in a way to form a nearly circular enamel lake in well-worn teeth. These lower teeth differ from those of all living species in having, the main cross lophs directed somewhat obliquely inward and backward instead of squarely across the long axis of the tooth.

The lower-jaw specimen shows nothing peculiar except that the capsular bulb at the base of the incisor is somewhat less prominent than is usual in the living species.

\section{Neofiber sp.}

Plate XXXV, figure 14.

A nearly complete cheek tooth, apparently the left upper middle one, from the Curtis locality (catalog No. 10527, U. S. Nat. Mus.), seems to represent the genus Neofiber. It is slightly smaller than the corresponding tooth of Neofiber alleni, with which I compared it, but has all its characteristics. Except the slight variation in size, they differ only in that the base of the fossil tooth is closed by the formation of rootlets, whereas the specimens of the living species examined seemed to indicate growth from a persistent pulp. However, this difference may be, in part, at least, an age character, as in the closely related genus $\mathrm{On}$ datra, in which both conditions are found on examining a number of specimens of various ages.

\section{Order LAGOMORPHA.}

Four species of Lagomorpha are represented in the collection, three from the Benson locality and one from the Curtis locality. They seem not to be referable to any living species, but the material representing them is too fragmentary to warrant any attempt at diagnostic descriptions.

\section{Species No. 1.}

Plate XXXV, figure 15.

Represented by a portion of a left lower jaw carrying $\mathrm{p}_{4}, \mathrm{~m}_{1}, \mathrm{~m}_{2}$ (broken), and the alveoli for the other two cheek teeth and the incisor, from the Benson locality (catalog No. 10530, U. S. Nat. Mus.). This specimen represents a species about the size of Lepus campestris, or slightly smaller, and it agrees with that species rather closely both in jaw and tooth characters.
Species No. 2.

Plate XXXV, figure 11.

Represented by two upper incisors (broken), a first lower cheek tooth of the left side, and a median lower cheek tooth of the left side, from the Benson locality (catalog No. 10529, U. S. Nat. Mus.).

These teeth represent a small species about the size of Sylvilagus aud. arizonae or Brachylagus idahoensis. However, there are some peculiarities in one or another of all these teeth that make uncertain their definite reference to either of these living genera. The incisors are of a type to fit in with either genus, although there is not quite the difference in relative size of the two lobes formed by the anterior longitudinal groove. In the molar tooth the posterior lobe is about intermediate in relative size bebetween that of $S$. aud. arizonae and $B$. idahoensis, and both lobes are somewhat less laterally expanded and less sharply angulate than in either of these species. The anterior lower cheek tooth, which is of the right side, is peculiar and differs from that of any living species that has come under my observation. It is of the same general form as that of $S$. aud. arizonae but is proportionately a little wider, being nearly as wide as long, and is void of any reentrant angles except the normal two outer ones. Moreover, the posterior one of these extends but little more than halfway across the tooth. In all living forms examined this reentrant either extends entirely across to the inner wall of the tooth or meets an opposing reentrant from the inner side.

\section{Species No. 3.}

Plate XXXV, figure 13.

In the collection from the Curtis locality are a portion of a right lower jaw carrying the anterior two cheek teeth (catalog No. 10528, U.S.Nat.Mus.) and a lower right anterior tooth of a second individual, which represent a species about the size of Lepus californicus erennicus, or somewhat smaller. The fossil species seems to differ from the latter, however, in the proportions of all the tooth lobes which are somewhat narrower and in having the anterior lobe of the first cheek and tooth set farther inward, so that the reentrant valley faces decidedly forward and outward, instead of almost directly outward, as in the living species. 
Cf. Lepus sp.

Plate $\mathrm{XXXV}$, figure 12 .

A fourth species of Lagomorpha (catalog No. 10535, U. S. Nat. Mus.) is represented in the material from the Benson locality by the two incisors of the right side in a fragment of the premaxillary. It differs from the others in having an unusually high inner ridge on the large incisor. In fact, the tooth is remarkable in that the plane of its upper face is very oblique to the perpendicular plane of the skull, as in Ochotona, but the plane of its lower surfaces is nearly at right angles to the perpendicular median plane of the skull, as in the true rabbits, and its summit has the characteristic wear of a short anterior chisel point and posterior ledge or shelf observed in all species of rabbits but not found in the Pica group. The longitudinal enamel groove is filled with cement, but this feature has not even a generic significance. As this form of incisor is suggested in some degree in certain species of Lepus, as $L$. siamensis, I regard the fossil specimen as belonging to that genus. 


\section{PLATES XXXIV-XXXV.}




\section{PLATE XXXIV.}

[All figures about twice natural size.]

Figure 1. Citellus cochisei Gidley, n. sp. Type. Upper cheek teeth of right side, crown view. No. 10490,

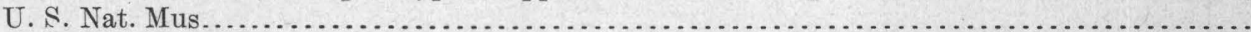

2. Citellus cochisei Gidley, n. sp. Portion of left lower jaw, tooth-crown view; 2a, side view. No.

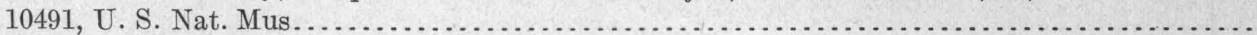

3. Citellus bensoni Gidley, n. sp. Type. Last left upper molar, crown view; 3a, 3b, right upper molar

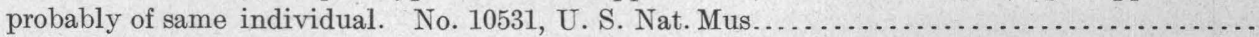

4. Citellus bensoni Gidley, n. sp. Lower cheek teeth in fragment of jaw of left side, crown view. No. 10532, U. S. Nat. Mus . . . . . . . . . . . . . . . . . . . . . . . . . . . . . . . . . . . . . . .

5. Geomys parvidens Gidley, n. sp. Type. Anterior portion of skull, palate view; 5a, side view.

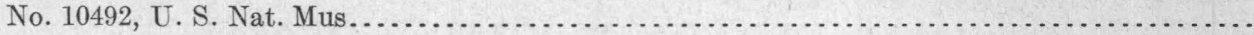

6. Geomys parvidens Gidley, n. sp. Portion of a right lower jaw, tooth-crown view; 6a, side view. No.

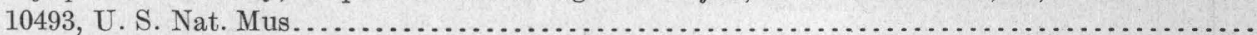

7. Geomys minor Gidley, n. sp. Type. Portion of a right lower jaw, tooth-crown view; 7a, side view.

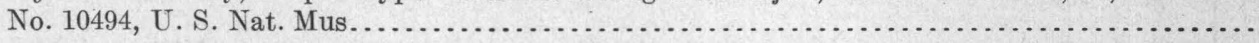

8. Geomys minor Gidley, n. sp. Upper incisor of left side, front view. No. 10534, U. S. Nat. Mus...

9. Cratogeomys bensoni Gidley, n. sp. Type. Portion of a left lower jaw, tooth-crown view; 9a, side

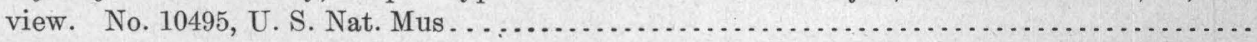

10. Cratogeomys bensoni Gidley, n. sp. Portion of a right lower jaw, tooth-crown view; 10a, side view.

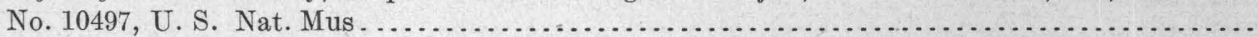

11. Cratogeomys bensoni Gidley, n. sp. Upper incisor of right side, front view. No. 10496, U. S. Nat. Mus.

12. Peromyscus brachygnathus Gidley, n. sp. Type. Portion of a right lower jaw, tooth-crown view;

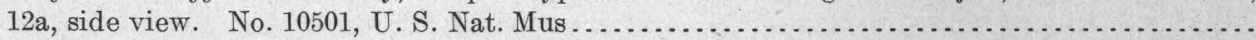

13. Peromyscus minimus Gidley, n. sp. Type. Portion of a left lower jaw, tooth-crown view; 13a,

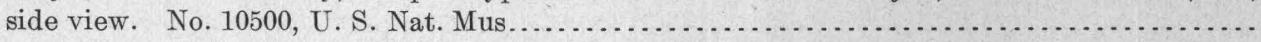

14. Peromyscus sp. Portion of a right lower jaw, side view. No. 10502, U.S. Nat. Mus.............

15. Eligmodontia arizonae Gidley, n. sp. Type. Greater portion of a right lower jaw, crown view;

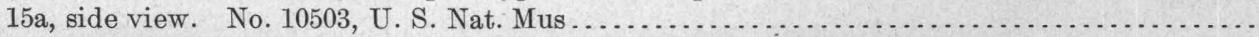

16. Dipodomys minor Gidley, n. sp. Type. Greater portion of a right lower jaw, tooth-crown view; 130 

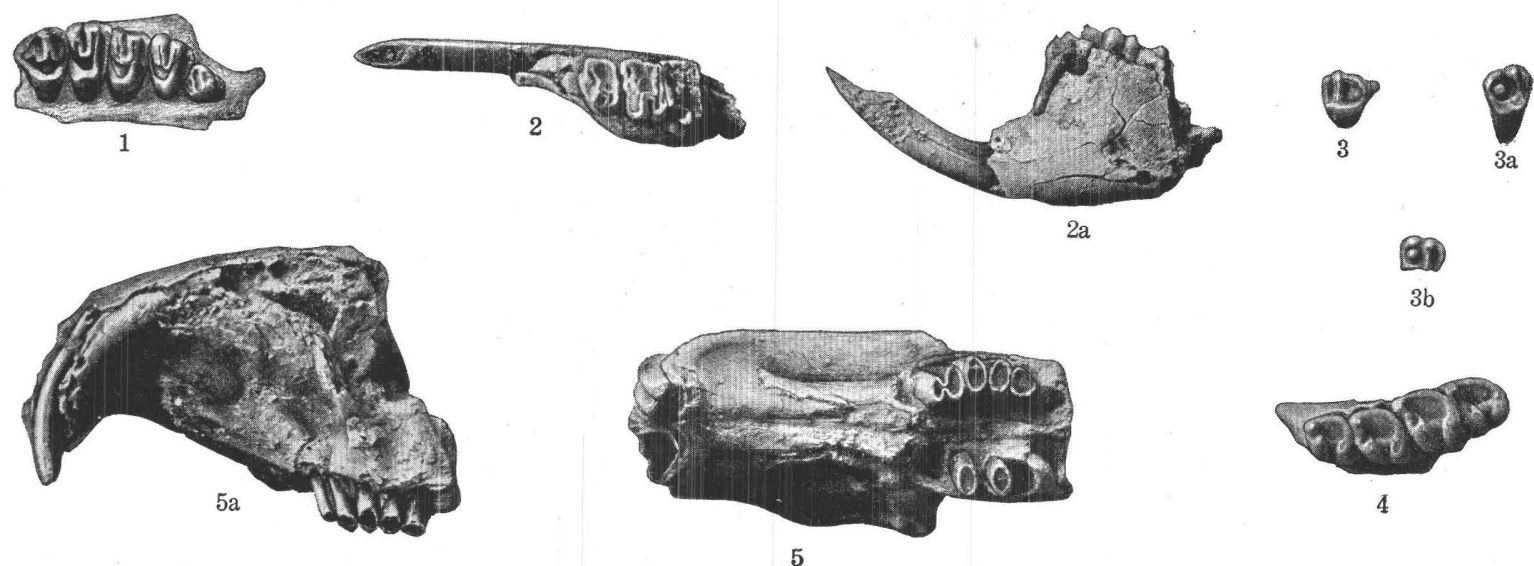

$3 \mathrm{~b}$
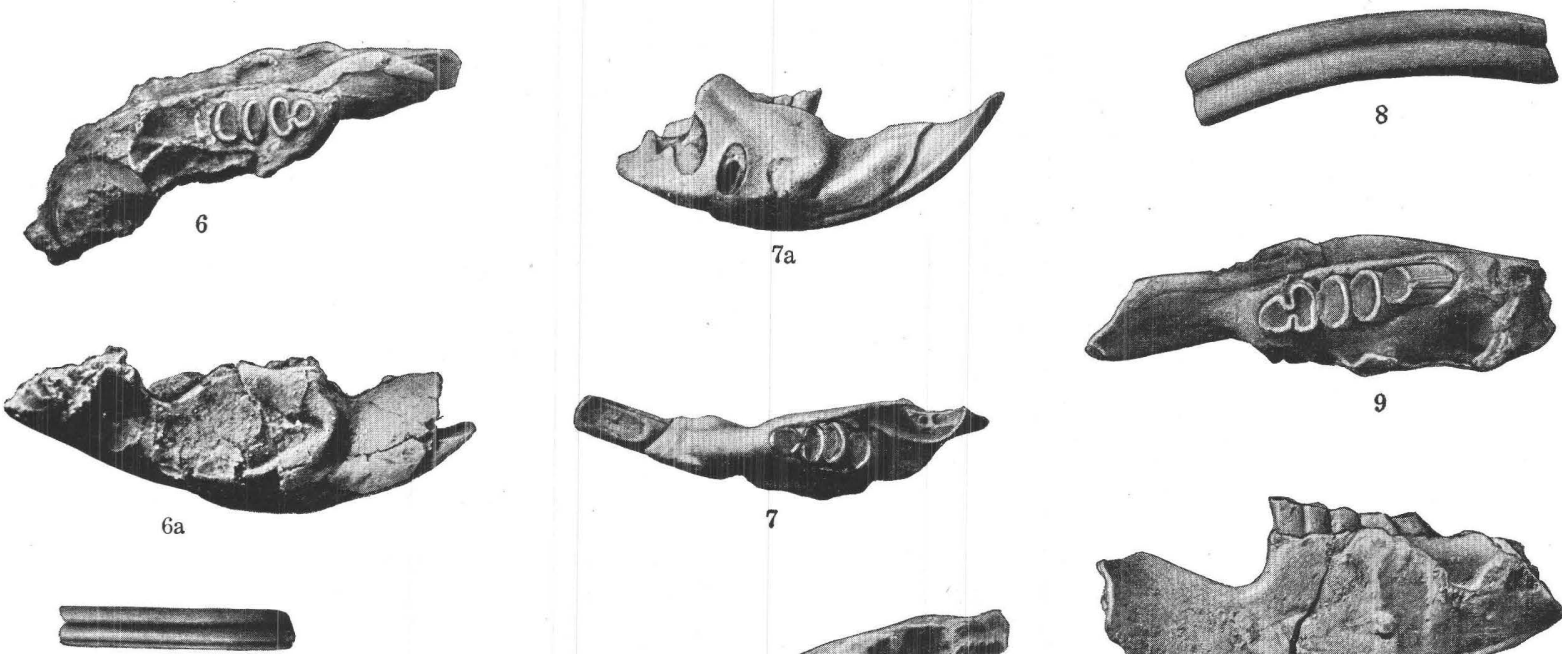

11
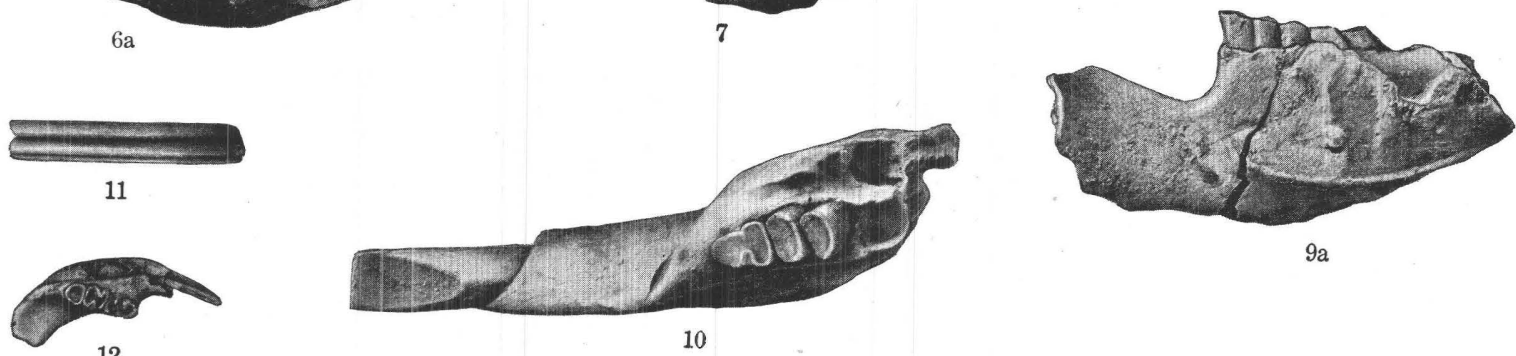

12

10
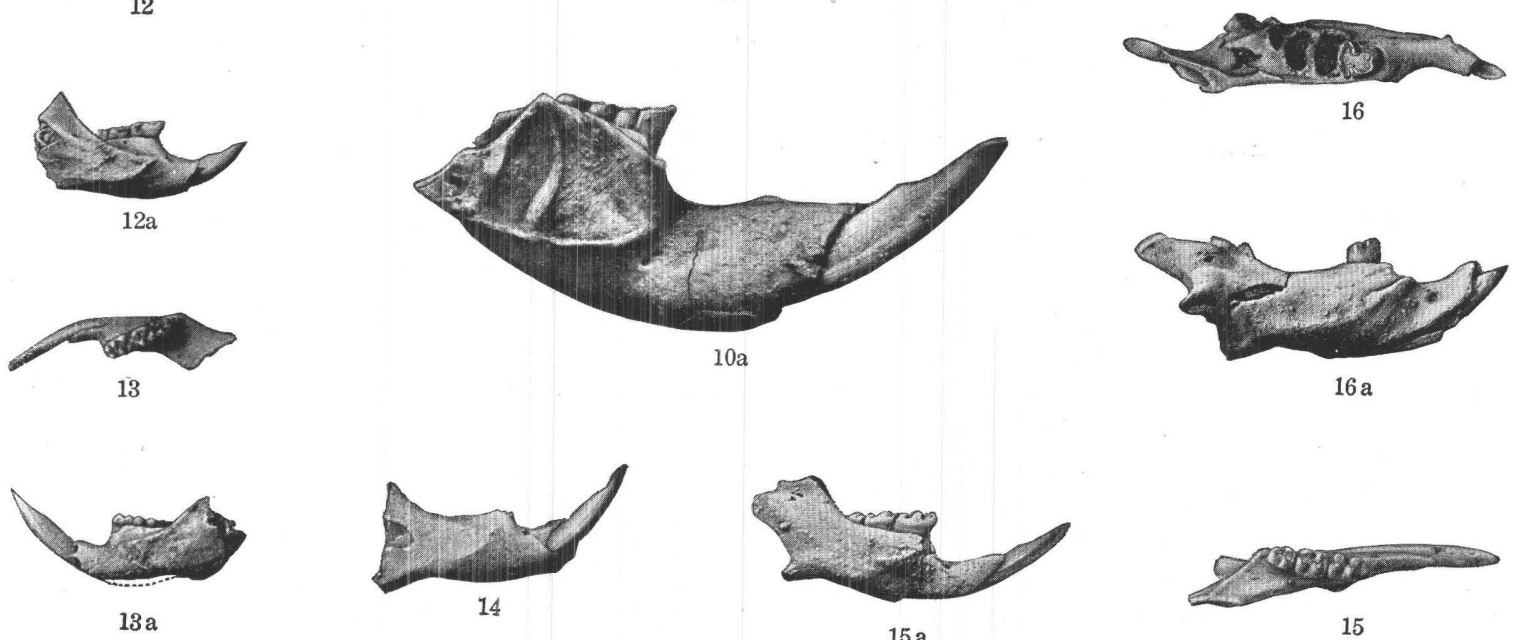

$15 \mathrm{a}$

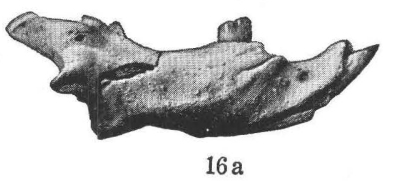

FOSSIL VERTEBRATES OF SAN PEDRo VALLEY, ARIZ. 


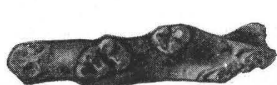

1

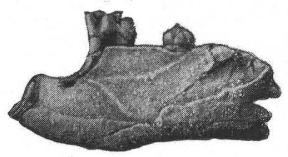

$1 \mathrm{a}$
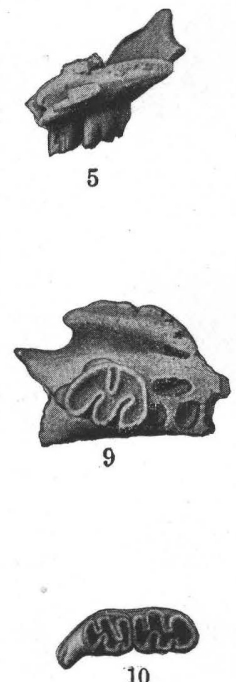

10
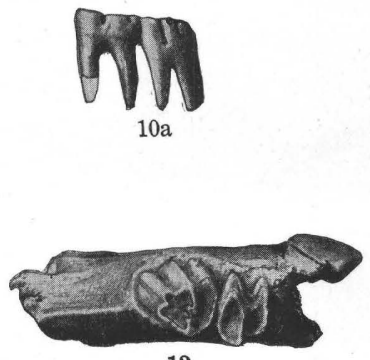

13
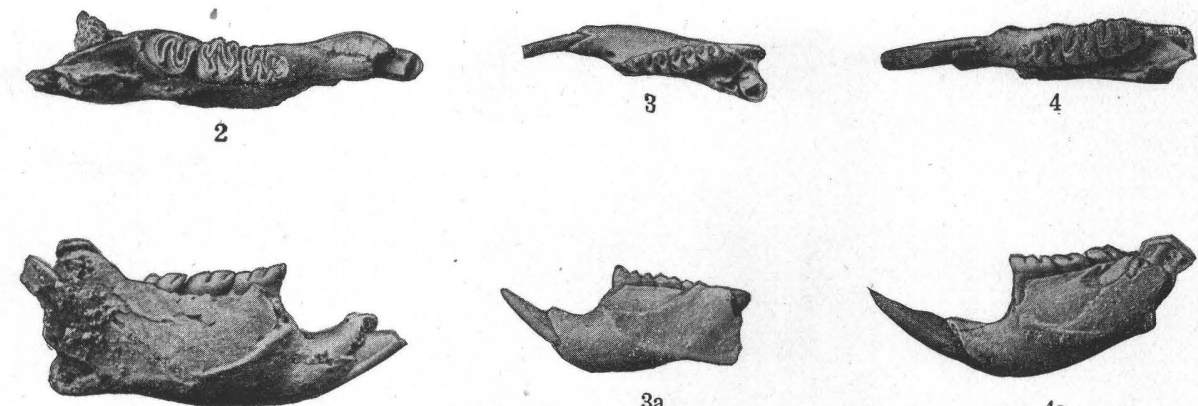

$2 \mathrm{a}$
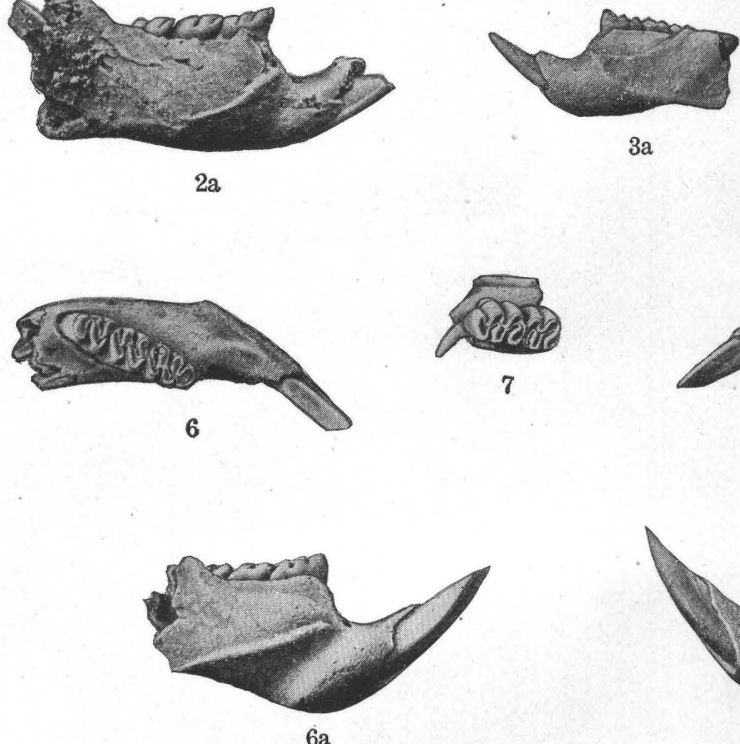

$3 a$

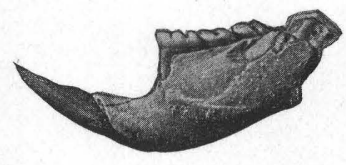

$4 \mathrm{a}$
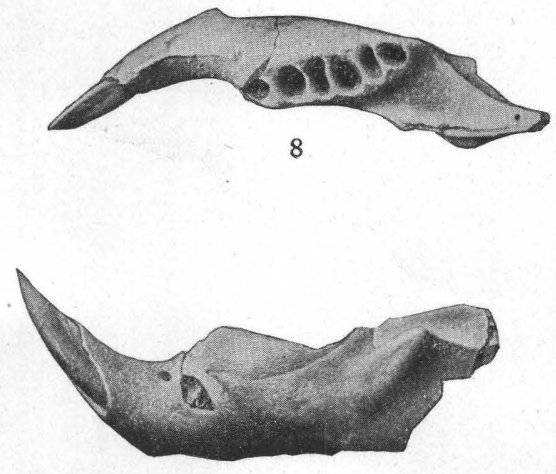

$8 \mathrm{a}$
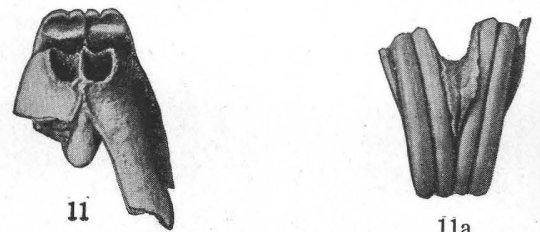

$11 \mathrm{a}$
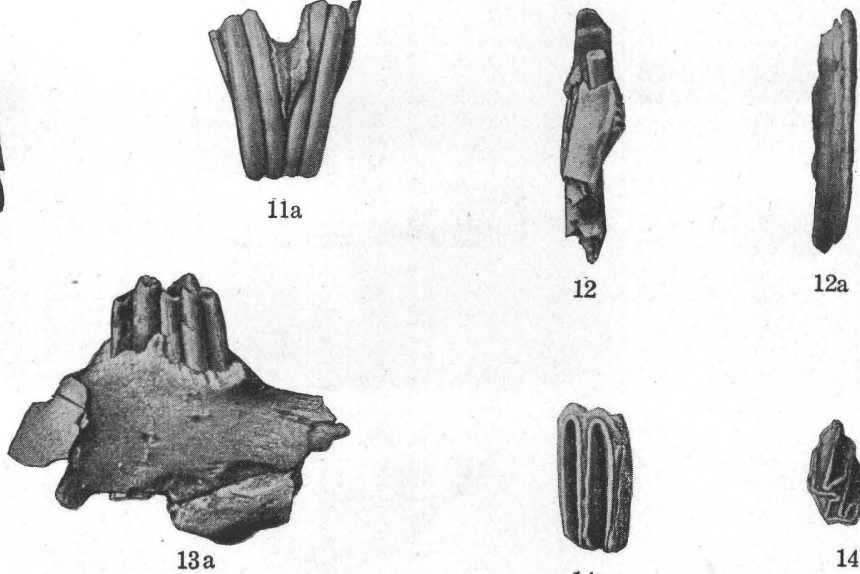

$14 \mathrm{a}$
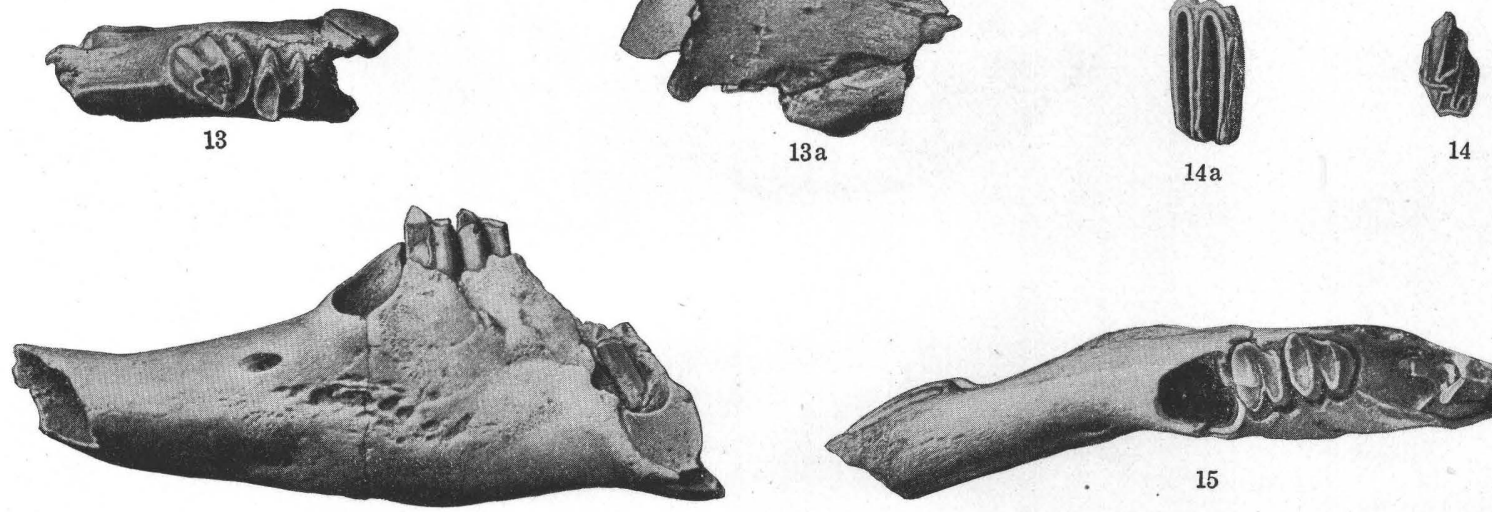

$15 \mathrm{a}$

FOSSIL VERTEBRATES OF SAN PEDRO VALLEY, ARIZ. 


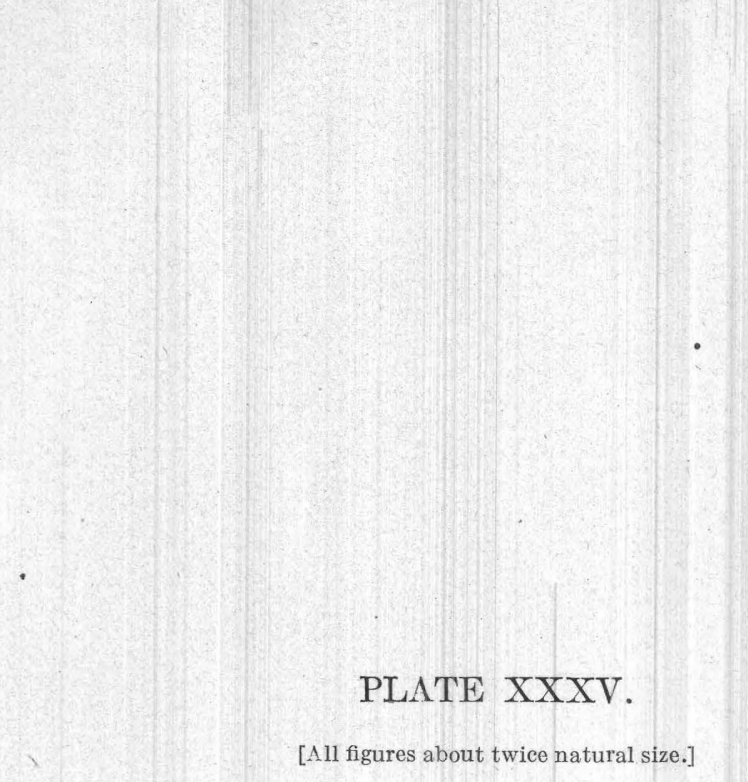

Page.

Figure 1. Onychomys pedroensis Gidley, n. sp. Type. Portion of a left lower jaw, tooth-crown view; 1a, side

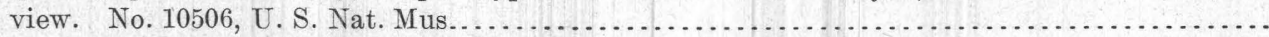

2. Sigmodon curtisi Gidley, n. sp. Type. Portion of a right lower jaw, tooth-crown view; 2a, side

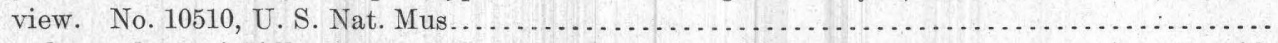

3. Onychomys bensoni Gidley, n. sp. Type. Portion of a left lower jaw, tooth-crown view; 3a, side

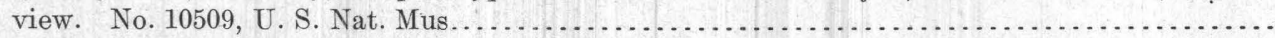

4. Sigmodon minor Gidley, n. sp. Type. Portion of a left lower jaw, tooth-crown view; 4a, side view.

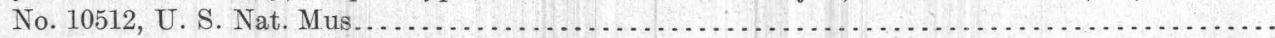

5. Sigmolon minor Gidley, n. sp. Two anterior cheek teeth in fragment of left maxillary, inner-side

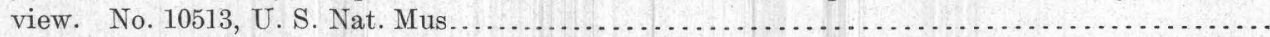

6. Sigmodon medius Gidley, n. sp. Type. Portion of a right lower jaw, tootl crown view; 6a, side

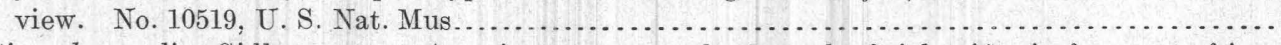

7. Sigmodon medius Gidley, n. sp. Anterior two upper cheek teeth of right si e, in fragment of jaw,

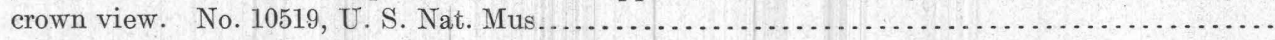

8. Neotoma fossilis Gidley, n. sp. Portion of a left lower jaw viewed from above; 8a, side view. No.

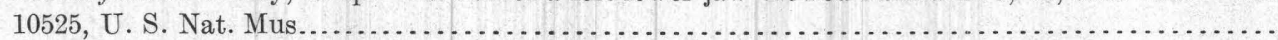

9. Neotoma fossilis Gidley, n. sp. Type. First upper cheek tooth of right side in fragment of maxillary,

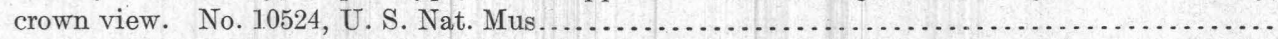

10. Neotoma fossilis Gidley, n. sp. Anterior two lower cheek teeth of right side, crown view; 10a, inner

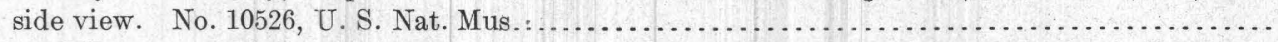

11. cf. Sylvilagus sp. Median incisors in fragment of premaxillary, palate view; 1la, front view. No. 10529, U. S. Nat. Mus.

12. Lepus sp. Two upper incisors of right side in fragment of premaxillary, palate view; 12a, front view.

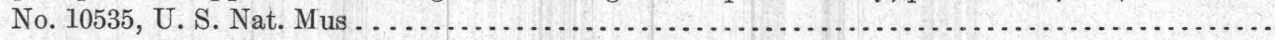

13. Lepus sp. cf. L. californicus. Anterior two cheek teeth of right side in fragment of lower jaw, crown view; 13a, outer side view. No. 10528, U. S. Nat. Mus.

14. Neofiber sp. Portion of a left upper molar, oblique crown view; $14 a$, outer side view. No. 10527 ,

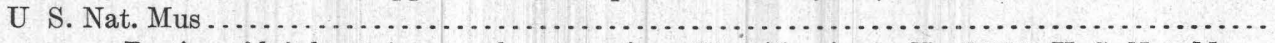

15. Lepus sp. Portion of left lower jaw, tooth-crown view; 15a, side view. No. 10530, U. S. Nat. Mus.. 